\title{
Geographic Distribution of the Anopheles labranchiae Species Malaria Vector in the Province of Sidi Slimane, Morocco
}

\author{
Mohamed Hadji, \\ Laboratoire de Biotechnologies, Environnement et Qualité, \\ Université Ibn Tofail, Faculté des Sciences, Kénitra, Maroc \\ Cellule Provinciale de Santé Environnement. \\ Délégation du Ministère de la Santé, Sidi Slimane, Maroc
}

Driss Belghyti,

Ali Hadji,

Laboratoire de Biotechnologies, Environnement et Qualité,

Université Ibn Tofail, Faculté des Sciences, Kénitra, Maroc

Samir Zahri,

Wafae Khirallah,

Laboratoire de botanique, biotechnologie et protection des Plantes, Université Ibn Tofail, faculté des Sciences, Kénitra, Maroc

\section{Mohamed El Assal,}

Cellule Provinciale de Santé Environnement.

Délégation du Ministère de la Santé, Sidi Slimane, Maroc

\begin{abstract}
The mosquitoes Culicidae have a medical and veterinary interest as they play an important role in the transmission of many parasitic and / or viral diseases and are a source of nuisance to humans. The province of Sidi Slimane remains exposed to the risk of emergence and recurrence of new cases of malaria due to the existence of breeding sites constituting a favorable biotope for the development and evolution of Culicidea, vectors of diseases. In the context of geographical distribution study of the Anopheles labranchiae specie in the province of Sidi Slimane during the period 20152017, twenty larval breeding sites were monitored and surveyed in time and space. We have mapped the positive larval breeding sites of Anopheles labranchiae, the main vector of malaria transmission in Morocco, and identified the localities at risk in order to facilitate the fighting operations and to maintain the epidemiological situation at zero cases of indigenous malaria in the zone of study.
\end{abstract}


Keywords : Anopheles labranchiae, Larvae, Malaria, Geographical Distribution, Sidi Slimane, Morocco

\section{Introduction}

Mosquitoes Culicidea play an important role in the transmission of many parasitic and or viral diseases (Malaria, Dengue, Chikungunya, Zika diseases, Nile fever, Yellow fever, Rift Valley fever, Equine encephalitis, Japanese encephalitis, Encephalitis Saint Louis), and constitute a crucial study material for entomologists. In Morocco since 2005, no cases of indigenous malaria have been recorded (Ministry of Health: DPRF, 2007. www.santé.gov.ma).

The study of the distribution of the species Anopheles labranchiea inventoried in the province of Sidi Slimane, which is considered as the main vector of indigenous malaria in Morocco (OMS 1993), is of paramount importance in determining areas at risk and facilitating the fight against this vector and any new malaria control strategy must take into account the concept diversity and that the measures recommended must be adapted to the situations local (Baudon, Carnevale, Ambroise-Thomas, Roux, 1987).

\section{Presentation of the study area}

The Province of Sidi Slimane, located between $34^{\circ} 16^{\prime}$ North and 5 - 55' West, is limited to the north and east by the Province of Sidi Kacem (region of Rabat - Salé - Kenitra); to the south-east by the prefecture of Meknes (Fes-Meknes region); to the south by the province of Khemisset (region of Rabat-Salé-Kenitra) and to the west by the Province of Kénitra (region of Rabat - Salé - Kenitra). It covers about $1492 \mathrm{~km}^{2}$. The population of Sidi Slimane is estimated at 320-407 peoples (Resentment general 2014), with an average density of 192 persons / $\mathrm{Km}^{2}$. According to the administrative division of June 2009, the province of Sidi Slimane is composed of 9 rural communes: Kcebia, Sfafaa, Boumaiz, Msaada, Ouled Hssein, Dar Belamri, Azghar, Oled Ben Hammadi, Amer Chamalia and two urban communes (or municipalities) : Sidi Slimane, its chief town, and Sidi Yahya of Gharb (Figure 1). 


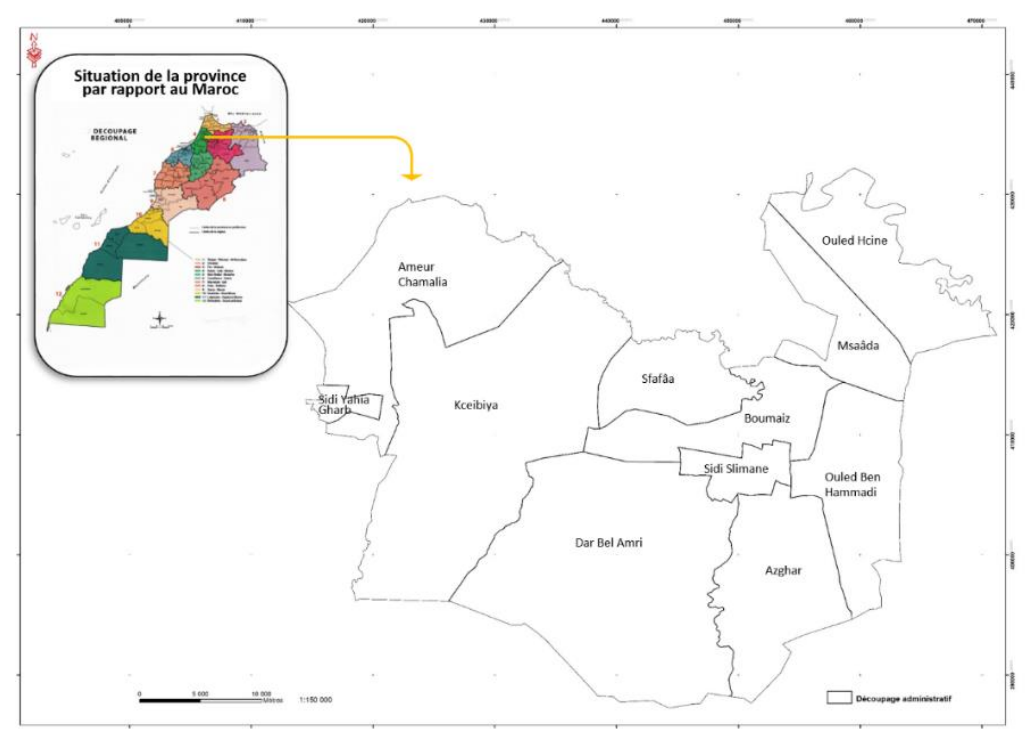

Figure 1. Map of the province of Sidi Slimane and its situation in Morocco (Source: Province of Sidi Slimane, Ministry of the Interior: Division of urban planning and Environment)

The province of Sidi Slimane is characterized by a temperate and humid climate, as well as abundant water resources, making the province of Sidi Slimane, an agricultural area of prime importance.

This province is a natural collector of surface waters. Its flat morphology (the majority of the plain having an inferior coast less than 12 m) disadvantages the evacuation of flood waters from the wadis to the sea. This makes the area highly vulnerable to flooding. The construction of the dams Idriss I (in 1973 on the Inouaene) and Al Wahda (in 1996) had the objective, among other things, of regulating the flows to be evacuated by the Sebou wadi and thus limiting the risks of flooding in the plain.

The existence of irrigated perimeters in the region can be divided in to two: those irrigated by the Beht and those by the Sebou (CID/INGEMA, 1985). The Sidi Slimane station (INGEMA, 1994) records minimal precipitation from other stations in the Gharb Chrarda Bni Hssen region due to the combination of the altimetric gradient effect and the continental gradient E-W which reflects the effect of the ocean. The most watered months are November, December and January and the driest months are June, July and August. The months of July and August are the hottest months while the coolest are December, January and February. The dry period is from May to September. 


\section{Materials and methods}

\section{Prospection of the larval breeding sites}

To locate the laying breeding sites preferred by Anopheles, it is essential to investigate systematically all the places that can serve as larval breeding sites, even those that are difficult to access. The choice of stations was made taking into account the proximity and the remoteness of the urban agglomerations from the larval breeding sites, the different types of aquatic environments (springs, merjas, dayas, oued, wells, etc.), epidemiological history of the locality of the larval breeding sites.

\section{Larval fishing}

Larval sampling was carried out using a mesh plankton with $0.1 \mathrm{~mm}$ of void net or using a rectangular white-bottomed plastic tray and place in a tray filled with water and then collected with an entomological pipette and store in a $70^{\circ}$ alcohol-containing tube (WHO 1993), with the name of the deposit and the date of sampling. While for shallow environments, a plankton net with a mesh size of $200 \mu \mathrm{m}$ and a diameter of $40 \mathrm{~cm}$ was used by dragging it in many places of each station to have a representative sample, this method of capture has been adopted by several authors (Blanchard, 1905). The vegetation is preserved in newspaper bearing the date of the vegetation survey, the name of the gite, locality and the commune.

The culicidae of different larval stages were harvested in different localities of Sidi Slimane province (Morocco) during the hydrological cycles from 2015 to 2017. A total of 07 health districts have been affected by this study: Sidi Yahia Gharb, Kceibia, Beggara, Dar Belamri, Laabiat, Oled Boutabet and Hay Essalam, (Table 4).

The sampling was carried out at precise intervals, during climatic conditions favorable to the sampling of species at the rate of two larval fisheries per month for the sentinel breeding sites and once a month for the other breeding sites. The first determinations of the culicidal species were made at the Malaria Laboratory of the Provincial Ambulatory Services Infrastructure (SIAAP) Kénitra. The examinations and identification of the harvested species were carried out at the Laboratory of Biology and Health: Team Environment and Parasitology of the Faculty of Sciences in Kénitra (Morocco). The identification of the species was carried out under the microscope according to the morphological characteristics (Himmi, Dakki, Trari, El Agbani, 1995), starting from the key of determination of the culicidae of Mediterranean Africa: Institute of Development and Research (IDR 1999), (Brunhes, Rhaim, Geoffroy \& Hervy, 1999): A new computerassisted identification tool. 


\section{Statement of the coordinates of larval breeding sites}

As part of the epidemiological surveillance, the fieldwork consisted of prospecting, locating the breeding sites by GPS and mapping the breeding sites. GPS statements have been exploited using the SIG tool 'Arcgis'. The cartographic bottom consists of topographic maps at 1/125000.

\section{IV- Results and discussion}

As part of the epidemiological surveillance, entomological surveys carried out in the province of Sidi Slimane, mapped the mosquito breeding sites, including those containing Anopheles: 6 positive anopheles larvae (Table 1), Which have a restricted appearance period ( Hadji et al. 2013), with different larval stages. In H/D Laabiat we recorded 3 positive breeding sites in Anopheles larvae (50\% of the positive breeding sites), 2 positive breeding sites in Anopheles larvae (33\% in H/D of kcebia) and a positive anopheles larval breeding sites at the H/D Beggara (17\%) (Figure 2), whereas in the other $\mathrm{H} / \mathrm{D}$ no positive breeding sites was recorded during the study period.

Table 1: Faunistic inventory in the health districts exposed to the risk of malaria.

\begin{tabular}{|c|c|c|c|}
\hline $\begin{array}{c}\text { Health } \\
\text { districts(H/D) }\end{array}$ & $\begin{array}{l}\text { Breeding } \\
\text { sites }\end{array}$ & $\begin{array}{c}\text { Type of breeding } \\
\text { sites }\end{array}$ & Identified Species \\
\hline \multirow[t]{2}{*}{ Kceibia } & $\begin{array}{c}\text { Dar } \\
\text { Gueddari }\end{array}$ & Merja & Anopheles labranchiae \\
\hline & Cheban & Fossé & $\begin{array}{c}\text { Anopheles labranchiae, Culex } \\
\text { pipiens }\end{array}$ \\
\hline \multirow[t]{3}{*}{ Laabiat } & Laabiat & Collection d'eau & $\begin{array}{c}\text { Anopheles labranchiae, Culex } \\
\text { pipiens }\end{array}$ \\
\hline & Soualem & Fossé & $\begin{array}{c}\text { Anopheles labranchiae, Culex } \\
\text { laticinctus }\end{array}$ \\
\hline & Tihli & Collection d'eau & $\begin{array}{c}\text { Anopheles labranchiae, Culex } \\
\text { pipiens }\end{array}$ \\
\hline Beggara & $\begin{array}{c}\text { Five } \\
\text { Coopératives }\end{array}$ & (Daya) & Anopheles labranchiae \\
\hline
\end{tabular}




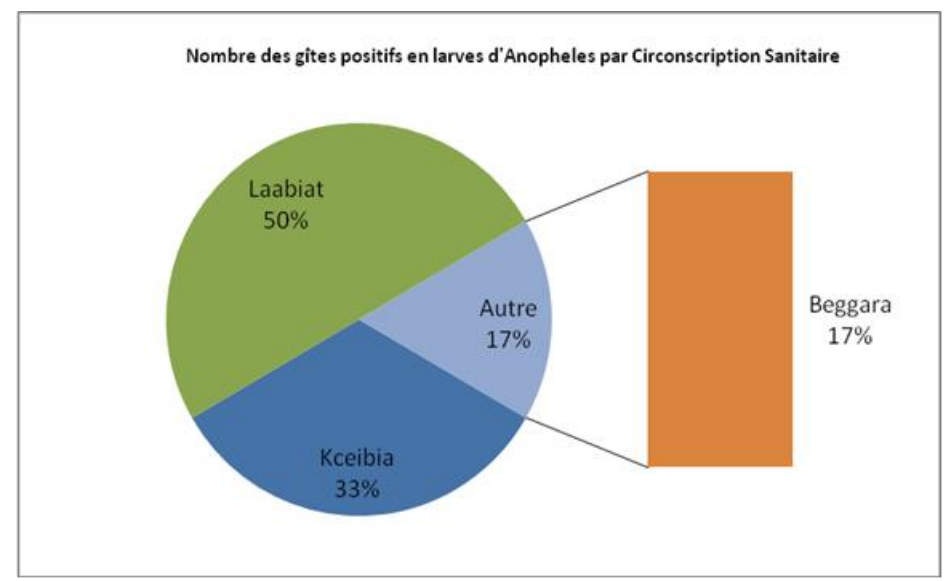

Figure 2: Number of positive breeding sites with Anopheles larval per health district

This study also allowed us to map and identify the preferred foyers of Anopheles (Figure 3), which are characterized by clean and clear water, riche with vegetation and sunny. The preference of this species for unpolluted waters has been reported by several authors (Gaud 1953, Senevet \& Andarelli 1956, Louah 1995), with vegetation consisting of filamentous algae, reed, Jonc, Lemna gibba, Typha angustifolia. In fact, the presence of vegetation in the Anophelian gites decreases the evaporation which favors the laying and the development of the eggs of certain species. As a result, the vegetation influences by organic mutter the physico-chemical characteristics of the water (Louah, Ramdani, Saoud et Mahjour 1995). The results of this study are useful for developing a control program, establishing surveillance measures, directing control operations, and maintaining monitoring and evaluation measures.

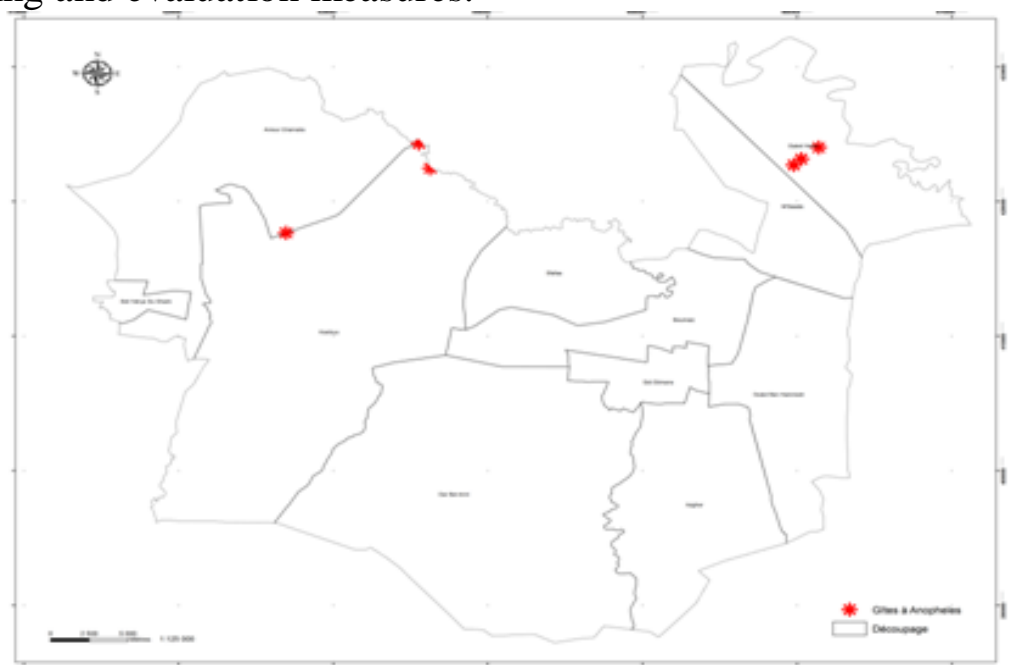

Figure 3. Distribution map of Anopheles in the Province of Sidi Slimane 


\section{V- Conclusion}

Through this study carried out in the province of Sidi Slimane, having the object of identifying the positive breeding sites in anopheline larvae, we have obtained results showing that the population of the health districts of Laâbiat and Kceibia is clearly exposed to the risk of re-emergence of malaria infection compared to populations of others health districts of the study area if surveillance, control and prevention activities are not maintained. This mapping database is a means of monitoring and follow-up for the health authorities of Sidi Slimane in order to target and guide the control operations and the screening activities and thus prevent the reintroduction of malaria in our country, in accordance with the national strategy of maintenance of the elimination of indigenous malaria in Morocco.

\section{References:}

1. Ministère de la Santé. Santé en chiffres. Bilan des maladies parasitaires 2005- 2007. Rabat : DPRF, 2007. www.santé.gov.ma.

2. OMS 1993. Lutte Antipaludique, Manuel du personnel du secteur, Ministère de la sante, Royaume du Maroc, (1996), 78 p.

3. Baudon D., Carnevale P., Ambroise-Thomas P., Roux J., 1987 - La lutte antipaludique en Afrique: de l'éradication du paludisme au contrôle des paludismes. Rev. Épidémiol. Santé Publ., 35 : 401-415.

4. CID/INGEMA, 1985. Etude du plan directeur intégré d'aménagement des eaux des bassins Sebou, Bou Regreg et Oum Er Rbia - Sous mission IB3-IB4- Etudes hydrogéologiques-Aquifère profond du Gharb.

5. INGEMA, 1994. Etude du système aquifère du Ghrab.

6. Blanchard R. 1905. Les moustiques. Histoire naturelle et médicale. Ed. F. R. De Rudeval. Paris, 634p.

7. Himmi O., Dakki M., Trari B., El Agbani M.A. 1995. Les Culicidae du Maroc : Clés d'identification, avec données biologiques et écologiques. Rabat : Institut Sciences, 1995, 《 Série zoologie 》44$51 \mathrm{p}$.

8. Brunhes J., Rhaim A., Geoffroy B. \& Hervy J.PP. (1999). - Les moustiques de l'Afrique méditerranéenne. Logiciel d'identification et d'enseignement. Montpellier, France, IRD \& IPT, CD-Rom collection Didactique IRD Editions.

9. Hadji M et al.2013. Etude entomologique, physicochimique des gites larvaires des moustiques (Anopheles, Culex).

10. Gaud J. (1953). Larves d'Anophèles à palettes thoraciques hyperchitinisées. Ann. Parasit., 4, pp. 326-328. 
11. Senevet G. \& Andarelli L. (1956). Les Anophèles de l'Afrique du Nord et du bassin méditerranéen. Encycl. Ent., Paris, 33, 280 pp.

12. Louah A. (1995). Ecologie des Culicidae (Diptera) et état du paludisme dans la péninsule de Tanger. Thèse doc. Etat ès-Sci Biol. Univ. Abdelmalek Essaadi, Fac. Sci., Tétouan, 266 pp.

13. Louah A., Ramdani M., Saoud Y. et Mahjour J. 1995. Biotypologie de la faune culicidienne de la péninsule tingitane. Bull. inst. Sci., Rabat, 1995, n¹9; pp 93-102. 